\title{
INFLUENCE OF CUTTING CONDITIONS ON THE SURFACE QUALITY AND GRINDING WHEEL WEAR DURING CYLINDRICAL GRINDING OF INCONEL 718
}

\author{
Tomas Baksa, Ondrej Hronek, Jindrich Farsky \& Miroslav Zetek
}
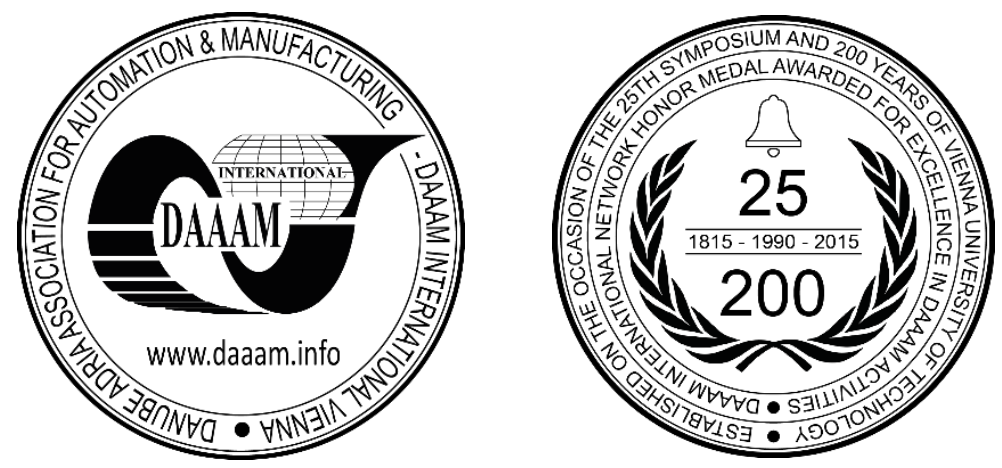

This Publication has to be referred as: Baksa, T[omas]; Hronek, O[ndrej]; Farsky, J[indrich] \& Zetek, M[iroslav] (2017). Influence of Cutting Conditions on the Surface Quality and Grinding Wheel Wear During Cylindrical Grinding of Inconel 718, Proceedings of the 28th DAAAM International Symposium, pp.0500-0505, B. Katalinic (Ed.), Published by DAAAM International, ISBN 978-3-902734-11-2, ISSN 1726-9679, Vienna, Austria

DOI: $10.2507 / 28$ th.daaam.proceedings.070

\begin{abstract}
This article deals with the experimental grinding of Inconel 718. This material is used for highly stressed components in the nuclear industry, such as combustion turbines. The material is very problematic for machining due to its rapid hardening and high heat generation. Two types of Inconel 718 in the form of testing bars were finished by cylindrical grinding using different cutting conditions and strategies. The main aim is to determine the impact of grinding conditions on the surface quality in terms of surface roughness after grinding. The resulting surface was scanned using an opticalscanning device to observe the topography of the ground surface. The grinding wheel was measured after grinding each bar to observe the wheel wear and the changes of the grinding wheel shape. The spindle load was monitored during grinding to see the effect of different strategies on the grinding process. The results from this work will be used in further studies and contribute to a better understanding of grinding Inconel 718.
\end{abstract}

Keywords: Grinding; Inconel 718; Roughness; Wheel wear; Cutting conditions

\section{Introduction}

Nickel-based alloys such as Inconel 718 are high-strength materials which are useful in many applications. It is used for example in the automotive, aerospace and nuclear industries for heat stressed components due to its excellent mechanical properties at high temperatures. Higher utilization of this material leads to higher demands on the productivity of component processing and production. However, the machining of Inconel 718 is very problematic due to its high cutting resistance. High strength at high temperatures and hardening during machining causes extreme cutting tool wear. Carbide cutting tools are widely used for machining Inconel 718 in the form of solid cutting tools or cutting inserts. Several studies [1,2] deal with the lengthening of the cutting tool life by modification of the cutting edge. It was found that using an optimal value of the edge radius is important for good adhesion of the thin layer and longer tool life. For high performance cutting, CBN cutting tools in the form of cutting inserts are used. However, CBN cutting tools are 
characterized by higher cost. CBN and carbide cutting inserts are used for example for turning cylindrical components. However, the surface quality after turning is limited by the technology and it is very difficult to achieve low roughness.

Mechanical properties of components predominantly depend on the surface quality after machining. Therefore it is very important to ensure the surface quality of components for applications in areas such as the nuclear and aerospace industries. Low roughness and high surface quality can be achieved by using grinding technology where the material is removed by geometrically undefined cutting edges. Compared to other machining processes, grinding is characterized by higher specific energy. Most of this energy is changed into heat which has harmful effects on the surface quality as well as the tool wear [3]. During grinding Inconel 718, there is an accumulation of heat in the grinding zone. This is caused by the lower thermal conductivity of the material. The accumulation of the heat results in severe thermal damage on the ground products. An appropriate choice of grinding wheel is necessary to ensure a stable and effective grinding process.

Some conventional abrasives such as diamonds cause a chemical affinity with Inconel, which leads to sticking of the grinding wheel chips on the grinding wheel. Corundum grinding wheels are suitable for grinding materials such as Inconel 718. An advantage of corundum grinding wheels is their low cost. However, the wheel wear during grinding is relatively high, which leads to frequent truing of the grinding wheel. Study [4] deals with an assessment of the embodied energy of a common corundum grinding wheel and a coated cemented carbide end mill. It was found that higher sustainability is achieved by using the grinding wheel rather than the end mill, despite a much higher embodied energy. This is because the grinding wheel is capable of machining a considerably higher volume of material.

The grindability of Inconel 718 using a corundum and a silicon carbide (SiC) grinding wheel is described in [5]. It was found that the corundum grinding wheel is more effective than the $\mathrm{SiC}$ wheel for grinding Inconel 718. The higher grinding temperature leads to a chemical reaction between $\mathrm{SiC}$ grit and the workpiece material which causes severe attrition wear. One way to reduce wheel wear is to use a suitable grinding wheel material. CBN grinding wheels are characterized by high wear resistance, which increases grinding wheel durability. This is important especially for profile wheels such as radius shape wheels where it is desirable to keep the shape of the grinding wheel for a long time.

Grinding Inconel 718 with different grinding wheels was investigated by Tso [6], where the effect of various process parameters on the surface roughness, dimension accuracy and the cutting force were observed. The experiments led to the conclusion that a CBN grinding wheel is more suitable for grinding Inconel 718 than the SiC and corundum wheels. The grinding process creates heat which can lead to residual tensile stress on the surface after grinding. It may cause micro-cracks on the surface which reduce the fatigue life of the components. To reduce the residual stress after grinding we must first ensure a suitable and stable grinding process by choosing the appropriate cutting parameters and environment.

According to [7], residual tensile stress can be transformed to compressive stress by embedding an added heat source inside the workpiece. The grinding environment plays a significant role in grinding nickel based superalloys such as Inconel. The effects of different grinding environments such as dry, minimum quantity lubrication (MQL) and CryoMQL on grinding and surface performance are described in [8]. It was found that a Cryo-MQL environment achieved better results in terms of grinding forces, temperature and roughness compared to other environments. Research [9] deals with the application of nanofluids in small quantity lubrication mode during grinding Inconel 718.

The main aim of this research is to determine the influence of several different cutting parameters on surface roughness after grinding and the wheel wear on a CBN grinding wheel.

\section{Grinding details}

Several testing bars of Inconel 718 were ground with the same CBN grinding wheel under different grinding conditions. All the test bars have the same profile shape and the same dimensions. Roughing of the profile was carried out on a turning machine with carbide cutting inserts. Grinding was performed on a CNC 5-axis tool grinding machine with high precision.

The dimensions of the test bar are shown in Fig. 1. Testing bars were turned to diameter 5.25 mm which gives an allowance of $0.25 \mathrm{~mm}$ on the diameter for grinding. The profile of the test bar is composed of a linear part and a radius on each side. Therefore the radius grinding wheel was used to ensure the smooth transition and point contact between the grinding wheel and the surface. A small grain size of the wheel was chosen to achieve low surface roughness. The parameters of the grinding wheel are given in Tab. 1 .

\begin{tabular}{|c|c|c|c|c|c|}
\hline Wheel shape & Diameter [mm] & $\begin{array}{c}\text { Abrasive rim } \\
\text { height [mm] }\end{array}$ & Radius [mm] & Grain size & $\begin{array}{c}\text { Clamping } \\
\text { diameter [mm] }\end{array}$ \\
\hline 3F1 & 150 & 3 & 2 & B33 & 32 \\
\hline
\end{tabular}

Table 1. Grinding wheel parameters 


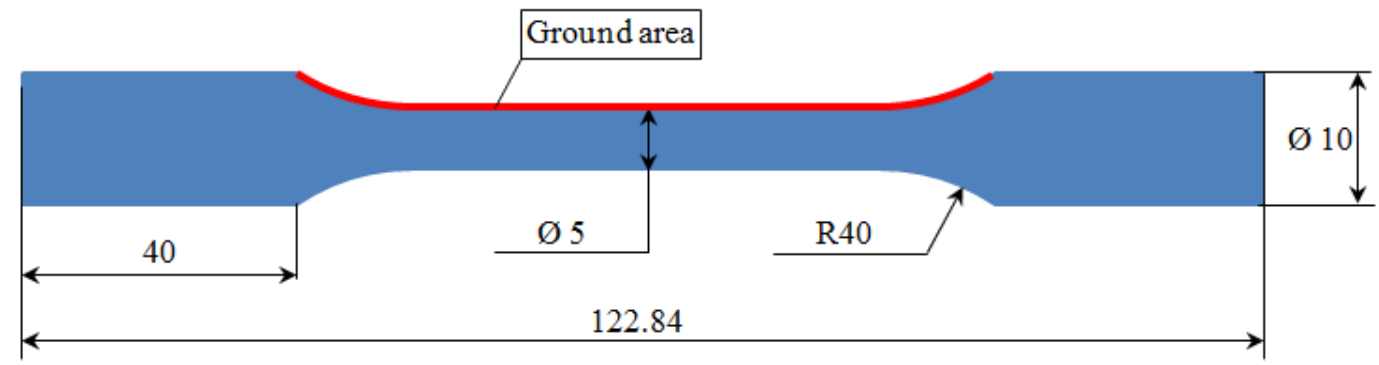

Fig. 1. Dimensions of the test bar

High-performance grinding fluid SintoGrind TTK was used to reduce temperature and friction during grinding. This mineral oil is designed for use in all grinding applications and for different materials. Coolant pipes were set to deliver the fluid to the grinding point. Coolant and the setting were constant for all cutting conditions. One cylindrical side of the testing bar was clamped into a collet of the machine and the second cylindrical side was supported by a steady bed to ensure a fixed position without bending. The steady bed of the support is V-shaped for a precise fit of the cylindrical part. Cutting conditions were changed during testing in terms of cutting speed, workpiece speed, feed rate, depth of cut and direction of rotation. The surface after cylindrical grinding was analysed using an optical-scanning device to measure the surface roughness. The grinding wheel profile was scanned before and during the grinding tests using an optical measuring device to observe the progress of the wheel wear.

Two types of Inconel 718 were tested during the experiment. Inconel 718 produced by conventional technology was used for grinding tests with different cutting conditions. Selected grinding conditions were used for grinding the second type of Inconel 718 which was produced by additive technology. The purpose of this is to observe the differences in grinding Inconel 718 produced by conventional and additive technology. Grinding was compared in terms of the surface roughness and the spindle load during grinding. Chemical composition of both materials is shown in Tab. 2 .

\begin{tabular}{|c|c|c|c|c|c|c|c|c|c|c|c|c|c|}
\hline$[\%]$ & $\mathrm{C}$ & $\begin{array}{l}\mathrm{Mn}, \\
\mathrm{Cu}\end{array}$ & Si & $\mathbf{P}, \mathbf{S}$ & $\mathrm{Cr}$ & Al & Mo & $\mathbf{N i}$ & $\mathbf{T i}$ & $\mathbf{F e}$ & $\mathbf{N b}$ & Co & B \\
\hline $\begin{array}{c}\text { Conventiona } \\
1\end{array}$ & 0.01 & 0.02 & 0.05 & $\begin{array}{c}<0.00 \\
4\end{array}$ & $\begin{array}{c}18 . \\
5\end{array}$ & $\begin{array}{c}0.5 \\
1\end{array}$ & $\begin{array}{c}3.0 \\
4\end{array}$ & $\begin{array}{c}54 . \\
2\end{array}$ & $\begin{array}{c}0.9 \\
5\end{array}$ & R17.64 & $\begin{array}{c}4.9 \\
5\end{array}$ & $\begin{array}{c}0.0 \\
3\end{array}$ & 0.004 \\
\hline $\begin{array}{l}\text { Additive } \\
\text { technology }\end{array}$ & $\begin{array}{c}<0.0 \\
8\end{array}$ & $<0.35$ & $\begin{array}{c}<0.3 \\
5\end{array}$ & $\begin{array}{c}<0.01 \\
5\end{array}$ & $\begin{array}{c}17 \\
- \\
21\end{array}$ & $\begin{array}{c}0.2 \\
- \\
0.8\end{array}$ & $\begin{array}{c}2.8 \\
- \\
3.3\end{array}$ & $\begin{array}{c}50 \\
- \\
55\end{array}$ & $\begin{array}{c}0.6 \\
5 \\
- \\
1.1 \\
5\end{array}$ & $\begin{array}{c}\text { balanc } \\
\mathrm{e}\end{array}$ & $\begin{array}{c}4.7 \\
5 \\
- \\
5.5\end{array}$ & $<1$ & $\begin{array}{c}<0.0 \\
6\end{array}$ \\
\hline
\end{tabular}

Table 2. Chemical composition of two types of Inconel 718

\section{Results and discussion}

Several different grinding conditions were used for grinding test bars made of Inconel 718 to find the best results in terms of surface roughness. The strategy for cylindrical grinding is shown in Fig. 2. Table 3 shows an overview of all the grinding conditions used.

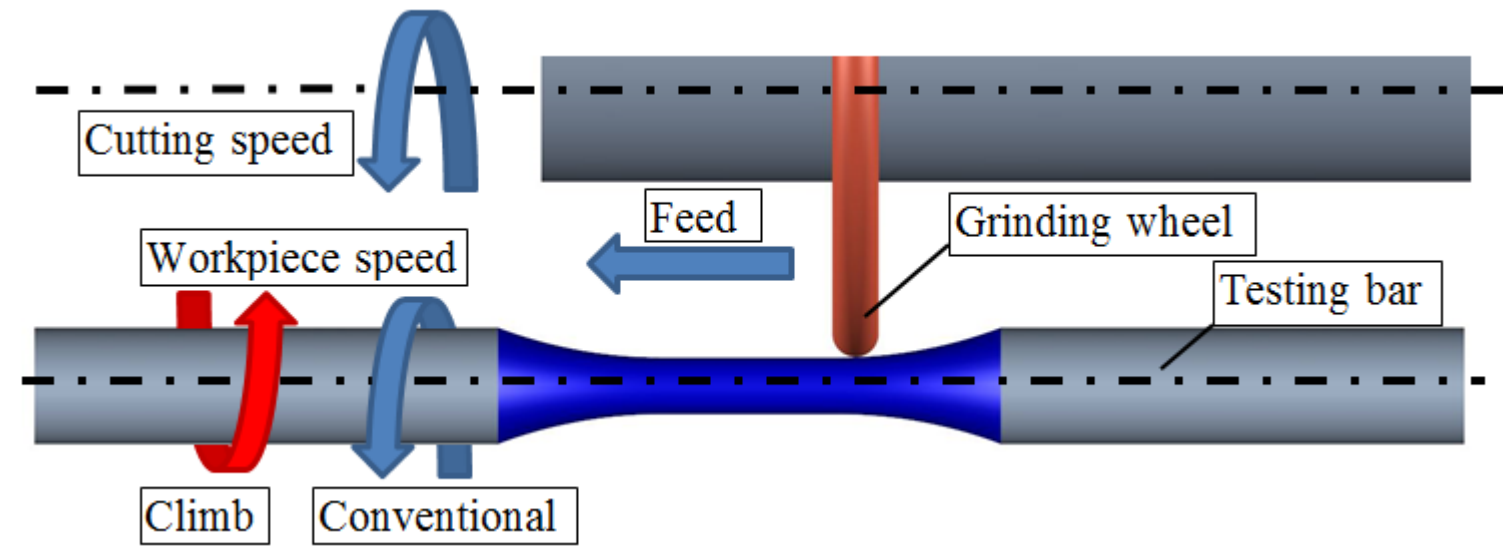

Fig. 2. Strategy of grinding 


\begin{tabular}{|c|c|c|c|c|c|}
\hline Test & $\begin{array}{c}\text { Depth of cut } \mathbf{a}_{\mathbf{p}} \\
{[\mathbf{m m}]}\end{array}$ & $\begin{array}{c}\text { Feed rate vf } \\
{[\mathbf{m m} / \mathbf{m i n}]}\end{array}$ & $\begin{array}{c}\text { Workpiece } \\
\text { speed } \mathbf{n}_{\mathbf{w}}[\mathbf{r p m}]\end{array}$ & $\begin{array}{c}\text { Cutting speed } \\
\mathbf{v}_{\mathbf{c}}[\mathbf{m} / \mathbf{s}]\end{array}$ & $\begin{array}{c}\text { Direction of } \\
\text { rotation }\end{array}$ \\
\hline $\mathrm{T} 01$ & 0.005 & 5 & 100 & 25 & Conventional \\
\hline $\mathrm{T} 02$ & 0.02 & 20 & 100 & 25 & Conventional \\
\hline $\mathrm{T} 03$ & 0.01 & 5 & 200 & 25 & Conventional \\
\hline $\mathrm{T} 04$ & 0.005 & 5 & 200 & 25 & Climb \\
\hline $\mathrm{T} 05$ & 0.005 & 5 & 200 & 25 & Conventional \\
\hline $\mathrm{T} 06$ & 0.005 & 3 & 200 & 25 & Conventional \\
\hline $\mathrm{T} 07$ & 0.005 & 5 & 100 & 30 & Conventional \\
\hline $\mathrm{T} 08$ & 0.005 & 5 & 100 & 35 & Conventional \\
\hline $\mathrm{T} 09$ & 0.005 & 5 & 150 & 35 & Conventional \\
\hline $\mathrm{T} 10$ & 0.005 & 5 & 200 & 35 & Conventional \\
\hline $\mathrm{T} 11$ & 0.003 & 5 & 100 & 25 & Conventional \\
\hline $\mathrm{T} 12$ & 0.005 & 5 & 100 & 25 & Conventional \\
\hline
\end{tabular}

Table 3. Grinding conditions

Grinding conditions in test T01 were chosen as the reference grinding conditions with small depth of cut, slow feed rate and slow workpiece speed. The cutting speed was determined based on the grinding wheel limitations and recommendations. Conditions in T01 were also used in T12 where the testing bar produced by additive technology was ground. Surface roughness after each test is shown in Fig. 3. Test T02 was characterized by deeper cut and higher feed rate compared to other tests. A deeper cut allows more material to be removed during one pass. A higher feed rate allows faster passes during grinding. This combination of both is suitable for achieving low grinding times. However, this test is characterized by high surface roughness due to high scallop height left after grinding. Higher scallop height is caused by low workpiece speed which leads to high feed rate per workpiece revolution. Cutting conditions in T02 were evaluated as suitable for roughing, but not for finishing of Inconel 718. In test T03, feed rate was rapidly decreased and the workpiece speed was increased to reduce scallop height after grinding. The depth of cut was also reduced by half. This resulted in a significantly better surface than for T02. Several different combinations of workpiece speed and cutting speed were tested in T07 - T10. It was found that all these tests achieve very similar results for surface roughness to the reference conditions (T01). The best results were achieved by T09 and T10 where a high cutting speed and high workpiece speed were used. This combination proved to be the best in terms of surface roughness after grinding. However, it is important to remember that high cutting speed of the grinding wheel and the high speed of the workpiece, whose vectors go against each other, cause higher friction which can lead to higher temperature and thermal damage of the ground surface. Reducing the depth of the cut in test T11 shows no difference in surface roughness compared to T01. Test T04 was characterized by a different rotation of the workpiece than in the other tests. Also the speed of the workpiece was increased to reduce scallop height. No significant difference between conventional and climb grinding was found in terms of surface roughness. In test T12, the test bar produced by additive technology was ground with the same cutting conditions as T01 (reference). The roughness and the grinding behaviour was comparable with T01.

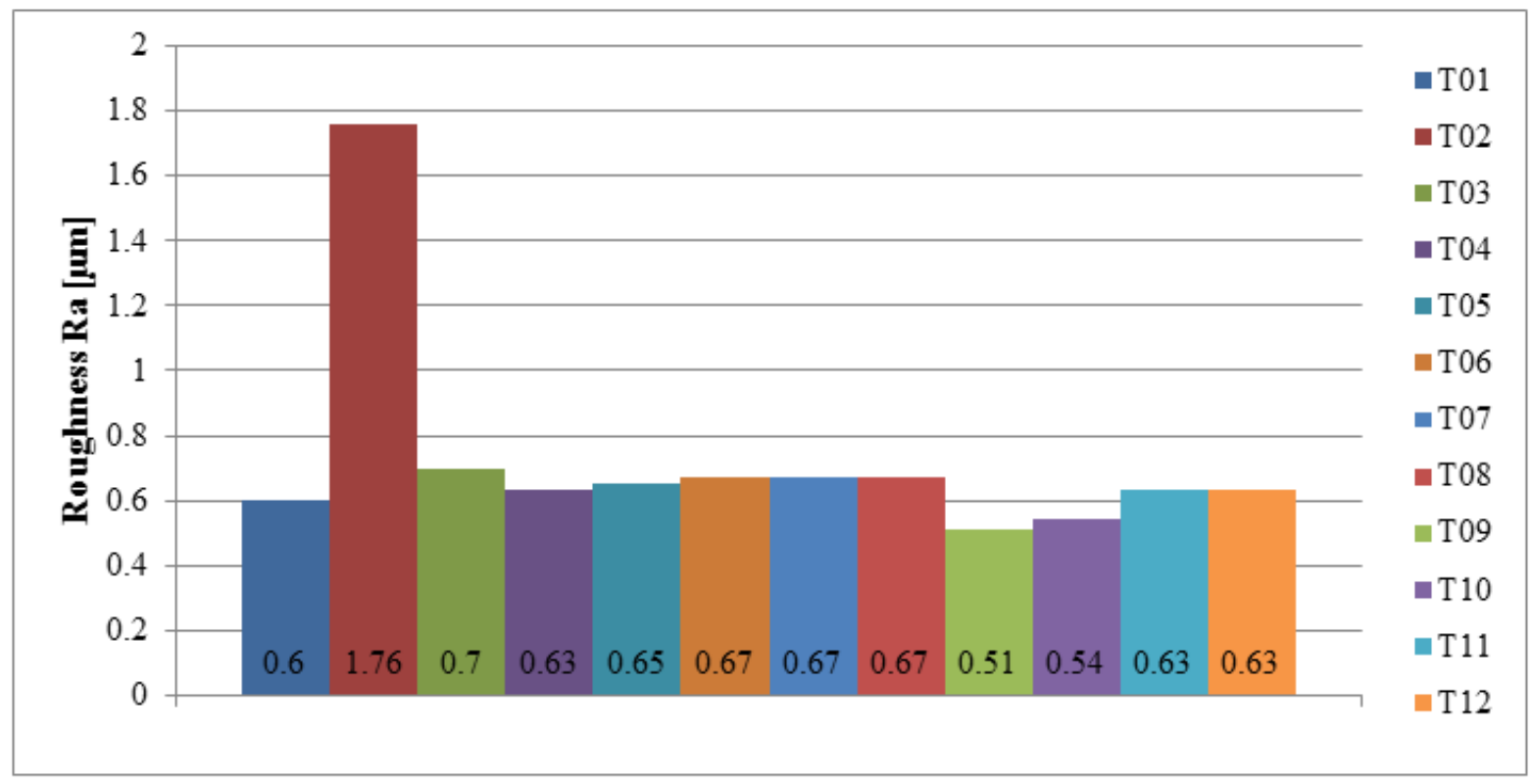

Fig. 3. Roughness after grinding Inconel 718 
The profile of the radius grinding wheel was measured during grinding using an optical measuring device. Fig. 4a shows the wear of the grinding wheel after grinding eight test bars. All test bars have the same allowance after turning, so the volume of material removed during grinding was constant for all the bars. The red zone shows that grinding was performed on the top of the wheel profile. It seems that the wheel wear is slightly unsymmetrical and greater wear occurred at the bottom of the profile. This may be caused by inaccurate roughing of the profile during turning, which leads to a shifting profile. The wheel wear is shown in Fig. 4b. The greatest increase in wheel wear occurred after grinding the first test bar, when the new grinding wheel became stable. This phenomenon was expected. After that, the grinding wheel wear linearly increases with the number of test bars. There was no significant difference between conventionally produced Inconel 718 and Inconel 718 produced by additive technology in terms of grinding wheel wear.

The spindle load was measured during the grinding test to see the influence of the cutting conditions on the grinding process. The spindle load was around $3.3 \%$ for all tests except test T02 where the spindle load was $3.5 \%$. This low spindle load was due to the small depth of cut, which was $0.005 \mathrm{~mm}$ for most tests. Test T02 achieved a slightly higher spindle load due to the greater depth of cut and higher feed rate. It can be said that grinding parameters such as cutting speed, workpiece speed and the feed rate have no significant influence on the spindle load if the depth of cut is small.

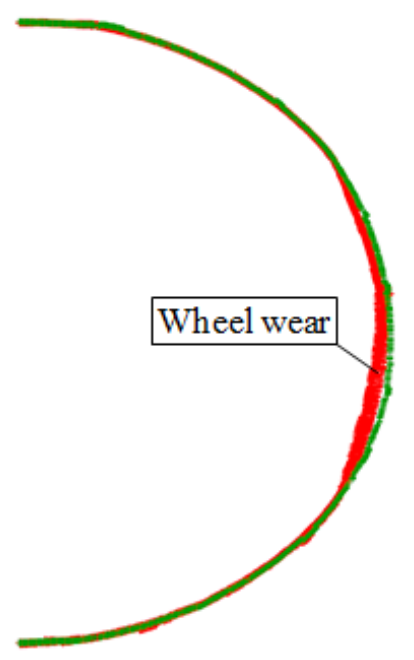

a)

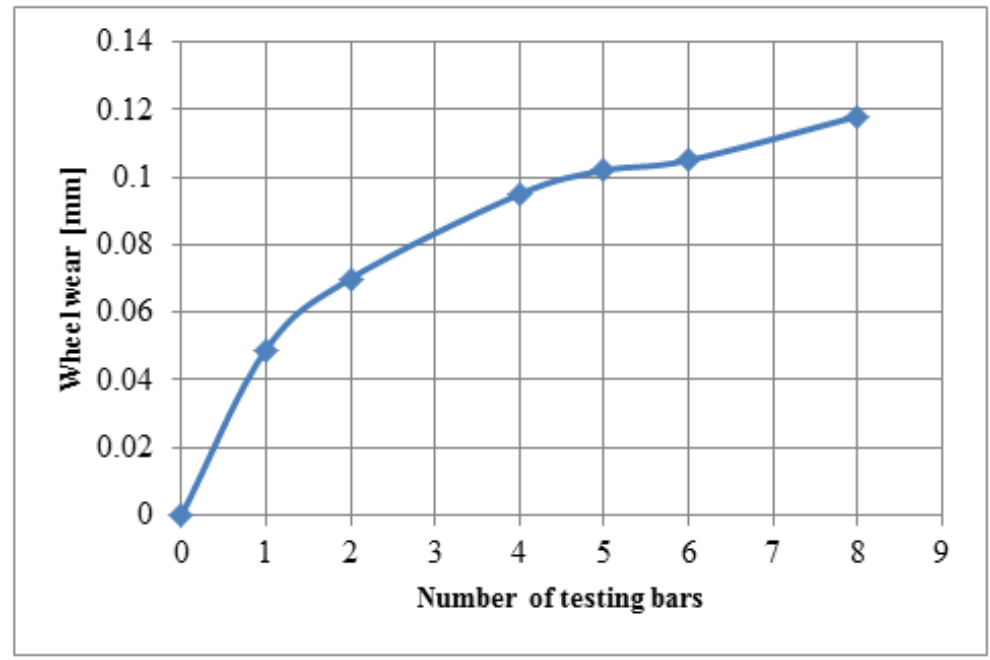

b)

Fig. 4. Profile of the grinding wheel (a) and the wheel wear (b)

\section{Conclusion}

This article deals with the experimental cylindrical grinding of Inconel 718 where several test bars with constant geometry were ground under different grinding conditions to see the effect on the surface quality in terms of the surface roughness. Inconel test bars were roughed using turning technology and then were finished using a radius CBN grinding wheel. The surface after grinding was scanned and measured to observe the surface roughness. It was found that tests T09 and T10 with a low feed rate, higher cutting speed $(35 \mathrm{~m} / \mathrm{s})$ and higher workpiece speed $(150-200 \mathrm{rev} / \mathrm{min})$ achieved the best results in terms of surface roughness. The low feed rate, respectively the ratio between feed rate and the workpiece speed, is very important for achieving a low scallop height and thus the low surface roughness. Test T02 with high feed rate and a deeper cut achieved the worst result in terms of roughness and it was evaluated as suitable for roughing. Changing the direction of rotation of the workpiece during test T04 makes no difference to surface roughness. The profile of the grinding wheel was measured during grinding to see the progress of the wheel wear. Monitoring of the spindle load showed that all tests gave a spindle load of lower than $4 \%$ due to the small depth of the cut during grinding. During the tests no less roughness than $\mathrm{Ra}=0.5 \mu \mathrm{m}$ was achieved. To achieve better surface roughness it would probably be necessary to use a grinding wheel with a smaller grain size. Two types of Inconel 718 were used for the test bars. The first was produced by conventional technology and the second by additive technology. It was confirmed that Inconel 718 produced by additive technology has the same grinding behaviour as conventional Inconel 718 in terms of achieved roughness, wheel wear and spindle load. The results from this research will be used for optimizing the cylindrical grinding of Inconel 718 and for better understanding of the behaviour during grinding. Further steps will be to determine the effect of different grinding wheels on grinding Inconel 718 to find out the most appropriate grinding wheel parameters.

\section{Acknowledgements}

This paper was supported by the programme of applied research, experimental development and innovation GAMA, No. TG02010011 - Support of UWB commercial opportunities. 


\section{References}

[1] Zetek, M.; Česáková, I.; \& Švarc, V. (2014). Increasing Cutting Tool Life when Machining Inconel 718, Procedia Engineering, vol. 69, pp. 1115-1124, ISSN: 1877-7058, Elsevier.

[2] Schorník, V.; Zetek, M.; \& Bakša, T. (2015). Durability of the cutting tool with different thin layers when Inconel 718 is machined, Annals of DAAAM and Proceedings of the International DAAAM Symposium, pp. 678-682, ISBN 978-3-902734-07-5, ISSN 1726-9679, Vienna, Austria.

[3] Fritsche A. \& Bleicher, F. (2015). Experimental Investigation of the Heat Flux Distribution in Grinding of Titanium Alloy, Procedia Eng., vol. 100, pp. 987-993, Elsevier.

[4] Kirsch, B.; Effgen, C.; Büchel, M. \& Aurich, J. C. (2014). Comparison of the Embodied Energy of a Grinding Wheel and an End Mill, Procedia CIRP, vol. 15, pp. 74-79, Elsevier.

[5] Sinha, M. K.; Setti, D.; Ghosh, S. \& Venkateswara Rao, P. (2016). An investigation on surface burn during grinding of Inconel 718, Journal of Manufacturing Processes, vol. 21, pp. 124-133, Elsevier.

[6] Tso, P.-L. (1995). Study on the grinding of Inconel 718, Journal of Materials Processing Technology, vol. 55, no. 3, pp. 421-426, Elsevier.

[7] Pei-zhuo, W.; Zhan-shu, H.; Yuan-xi, Z. \& Shu-sen, Z. (2017). Control of Grinding Surface Residual Stress of Inconel 718, Procedia Engineering, vol. 174, pp. 504-511, Elsevier.

[8] Balan, A. S. S.; Vijayaraghavan, L.; Krishnamurthy, R.; Kuppan, P. \& Oyyaravelu, R. (2016). An experimental assessment on the performance of different lubrication techniques in grinding of Inconel 751, Journal of Advanced Research, vol. 7, no. 5, pp. 709-718, Cairo University, Elsevier.

[9] Sinha, M. K.; Madarkar, R.; Ghosh, S. \& Rao, P. V. (2017). Application of eco-friendly nanofluids during grinding of Inconel 718 through small quantity lubrication, Journal of Cleaner Production, vol. 141, pp. 1359-1375, Elsevier. 